\title{
EFEKTIVITAS REBUSAN DAUN SIRIH MERAH (PIPER BETLE CROCATUM) DAN REBUSAN DAUN SIRIH HIJAU (PIPER BETLE LINN) TERHADAP PUBERTY GINGIVITIS
}

\author{
Culia Rahayu ${ }^{1 *}$ Salikun $^{2}$ \\ ${ }^{1}$ Dental Therapy, Poltekkes Kemenkes Tasikmalaya, Jawa Barat, Indonesia \\ ${ }^{2}$ Dental Therapy, Poltekkes Kemenkes Semarang, Jawa Tengah, Indonesia \\ "culiarahayu@yahoo.com
}

\begin{tabular}{ll}
\hline & ABSTRAK \\
\hline Kata kunci: & Tujuan dari penelitian ini adalah mengetahui efektivitas rebusan \\
Daun Sirih Merah (Piper Betle & daun sirih merah (piper betle crocatum) dan rebusan daun sirih \\
Crocatum), Daun Sirih Hijau & MTs Nuper betle linn) terhadap puberty gingivitis kelas VIII SMPN \\
(Piper Betle Linn), Puberty & dilakukan adalah penelitian eksperimen semu (quasi experiment) \\
Gingivitis & dengan rancangan two group pre and post test design. Populasi \\
& dalam penelitian ini adalah murid kelas VIII MTs Nurul Falah \\
& Kawalu Kota Tasikmalaya. Teknik pengambilan sampel adalah \\
& purposive sampling yaitu pengambilan sampel yang didasarkan \\
& pada suatu pertimbangan tertentu yang dibuat oleh peneliti \\
& sendiri sebanyak 40 orang. Teknik pengumpulan data untuk \\
& variabel Rebusan daun sirih merah Dan rebusan aun sirih hijau \\
& menggunakan dafttar ceklis sedangkan variabel terikat Puberty \\
& Gingivitis dengan cara Probbing. \\
\hline
\end{tabular}

Key word:

Piper Betle Crocatum, Piper Betle Linn, Puberty Gingivitis

\begin{abstract}
The purpose of this study was to determine the effectiveness of the red betel leaf decoction (piper betle crocatum) and the green betel leaf decoction (piper betle linn) against puberty gingivitis class VIII of SMPN MTs Nurul Falah Kawalu, Tasikmalaya City. This type of research is quasi-experimental research with a two group design pre and post test design. The population in this study were eighth grade students of MTs Nurul Falah Kawalu, Tasikmalaya City. The sampling technique is purposive sampling that is sampling based on a particular consideration made by the researchers themselves as many as 40 people. Data collection techniques for the variable red betel leaf decoction and green betel leaf decoction using a checklist list while the dependent variable Puberty Gingivitis by means of Probbing
\end{abstract}

\section{PENDAHULUAN}

Kesehatan merupakan hal yang dicari oleh semua orang. Menurut World Health Organization (WHO) kesehatan adalah suatu keadaan sehat yang utuh secara fisik, mental, dan sosial serta bukan hanya merupakan bebas dari penyakit, cacat atau kelemahan. (Maulana, 2009). Pembangunan kesehatan diarahkan untuk meningkatkan kesadaran, 
kemauan dan kemampuan hidup sehat bagi setiap orang agar peningkatan derajat kesehatan masyarakat yang setinggi-tingginya dapat terwujud (Kemenkes, 2010). Salah satu cara meningkatkan derajat kesehatan adalah dengan cara menjaga kesehatan gigi dan mulut, karena kesehatan gigi dan mulut memiliki peranan yang besar dalam kehidupan manusia, sebab gigi geligi kita memiliki pengaruh yang penting dalam perilaku manusia sehari-hari (Suryawati, 2010). Hal ini dikarenakan gigi dan mulut merupakan pintu gerbang masuknya makanan dan minuman yang diperlukan bagi tubuh manusia, karena itu sangat penting menjaga kesehatan gigi dan mulut untuk menunjang kualitas kehidupan yang lebih baik. (Sariningsih, 2014)

Upaya meningkatkan kesehatan gigi dan mulut adalah untuk menunjang kualitas kehidupan yang lebih baik, kita bisa menggunaan obat-obatan baik itu untuk pencegahan maupun penyembuhan. Obat-obatan itu dapat berupa yang berbahan dasar obat kimia sintetik maupun yang berbahan dasar tanaman obat tradisional atau herbal. Obat tradisional sendiri menurut Rosdiana dan Pratiwi (2014) mempunyai keunggulan dan kelebihan salah satunya tidak mempunyai efek samping sehingga lebih aman dibandingkan dengan obat kimia sintetik. Pemanfaatan obat tradisonal sendiri telah berlangsung sejak ribuan tahun yang lalu baik untuk pencegahan maupun pengobatan, salah satu tanaman yang dipakai sebagai obat tradional dalah daun sirih (piper betle). Ada berbagai macam jenis daun sirih, diantaranya adalah daun sirih hijau (piper betle linn) dan daun sirih merah (piper betle croctum). Pada dasarnya sirih dapat tumbuh diberbagai jenis tipe tanah dengan struktur sedang, asalkan tanahnya subur. Ketinggian tempat tumbuh berkisar 200-1000 m dpl. Tanaman sirih akan menghasilkan daun segar bila mendapatkan cahaya matahari penuh. Tanah sirih dapat tumbuh baik di daerah dengan iklim sedang sampai basah. Jenis tanah yang diinginkan adalah tanah yang kaya humus dan subur. (Mahendra, 2006). Daun sirih hijau memiliki nama ilmiah piper betle linn, nama asing ju jiang (cina), dan nama daerah suruh (jawa); sureuh (sunda); base (bali); leko, kowak, malo, malu (nusa tenggara); dontile, parigi (sulawesi), gies, bido (maluku); sirih, ranub, sereh, sirieh (melayu). (Mahendra, 2006)

Sudewo (2010) menyatakan dalam bukunya Basmi Penyakit dengan Sirih Merah, bahwa daun sirih merah (piper betle crocatum) mengandung flavonoid, alkaloid, senyawa polifenolat, tannin dan minyak atsiri yang dapat digunakan sebagai obat kumur untuk mengobati gusi berdarah (radang gusi). Selain daun sirih merah yang digunakan sebagai obat kumur, ada juga daun sirih hijau (paper betle linn). Sirih hijau (piper betle linn) menurut Rosdiana dan Pratiwi (2014) memiliki kandungan minyak atsiri, fenil propane, astragol, kavicol, hidroksida kavicol, kavibetol, caryophlyllene, cineole, allylpyrokatekol, cadidine, tannin, diastase, pati, terpennena, dan sedikit gula yang memiliki khasiat untuk mengobati gusi berdarah dan juga bengkak.

Gusi bengkak, tampak kemerahan mengkilap dan licin, serta cenderung mudah berdarah terutama saat menyikat gigi merupakan tanda peradangan pada gusi (gingivitis). Penyebab terjadinya gingivitis ini merupakan akibat dari plak (dental plaque) yang menumpuk pada leher gigi yang tidak dibersihkan. Plak bisa disebut juga dengan biofilm yang berwarna kuning pucat serta berkembang secara alami pada gigi (Mega, N., dkk., 2019). . Iritan kimiawi yang dihasilkan plak memasuki gusi melalui lekukan dangkal yang terdapat pada perbatasn gusi dan gigi. Lama kelamaan plak tersebut mengiritasi gusi sehingga terinfeksi dan mudah berdarah. (Wijayakusuma, 2008). Selain faktor plak atau kebersihan mulut, faktor lain penyebab gingivitis adalah faktor hormonal yang tidak seimbang, biasanya terjadi pada penderita diabetes, ibu hamil dan pada usia remaja (pubertas). (Kristiani., dkk, 2008). Gingivitis pada usia remaja atau pubertas (10-19 tahun) (DepKes RI, Cit. Sulistyowati dan Senewe, 2007) disebut juga Puberty gingivitis, karena pada masa ini tubuh mulai memproduksi hormon-hormon seks seperti hormone 
testosterone pada laki-laki dan hormone progesteron pada perempuan, sehingga hormon dalam tubuh menjadi tidak seimbang (Kartono, 2007).

Berdasarkan pra penelitian yang dilakukan peneliti pada murid kelas VIII B dan D MTs Nurul Falah Kawalu Kota Tasikmalaya yang berjumlah 70 orang, terdapat 40 orang anak yang mengalami gingivitis dengan tanda gusi berdarah saat menyikat gigi, terdapat pembengkakan pada gusi (gingiva), tampak kemerahan dan interdental papil membulat (Kristiani dkk, 2008). Berdasarkan latar belakang tersebut maka tujuan dari penelitian ini adalah mengetahui efektivitas rebusan daun sirih merah (piper betle crocatum) dan rebusan daun sirih hijau (piper betle linn) terhadap puberty gingivitis kelas VIII SMPN MTs Nurul Falah Kawalu Kota Tasikmalaya

\section{METODE}

Jenis penelitian yang dilakukan adalah penelitian eksperimen semu (quasi experiment) dengan rancangan two group pre and post test design (Notoatmodjo, 2005). Penelitian ini bertujuan untuk mengetahui pengaruh berkumur rebusan daun sirih merah (piper betle crocatum) dan rebusan daun sirih hijau (piper betle linn) terhadap angka gingival index responden diukur sebelum dan sesudah perlakuan. Populasi dalam penelitian ini adalah murid kelas VIII MTs Nurul Falah Kawalu Kota Tasikmalaya. Teknik pengambilan sampel adalah purposive sampling yaitu pengambilan sampel yang didasarkan pada suatu pertimbangan tertentu yang dibuat oleh peneliti sendiri sebanyak 40 orang, berdasarkan ciri atau sifat-sifat populasi yang sudah diketahui sebelumnya, kriteria tertentu berdasarkan tujuan penelitian dan sifat sampel dapat diterima mewakili populasinya. (Arikunto, 2010). Teknik pengumpulan data untuk variabel Rebusan daun sirih merah Dan rebusan aun sirih hijau menggunakan dafttar ceklis sedangkan variabel terikat Puberty Gingivitis dengan cara Probbing.

\section{HASIL DAN PEMBAHASAN}

Penelitian tentang efektivitas rebusan daun Sirih Merah (piper betle crocatum) dan Daun Sirih Hijau (piper betle linn) terhadap gingivitis pada remaja pubertas Kelas VIII MTs Nurul Tahun 2015. Sampel penelitian ini melibatkan siswa kelas VIII sebanyak 40 orang yang dibagi menjadi dua kelompok perlakuan, yaitu 20 orang siswa yang diberi pengarahan untuk berkumur rebuasan daun sirih merah dan 20 orang lagi diberi pengarahan untuk berkumur rebusan daun sirih hijau.

Pengukuran peradangan gingiva sebelum berkumur rebusan daun sirih dapat dilihat pada tabel 1 dibawah ini :

Tabel 1 : Distribusi frekuensi peradangan gingiva sebelum perlakuan

\begin{tabular}{cccccc}
\hline No & $\begin{array}{c}\text { Kriteria } \\
\text { Peradangan } \\
\text { Gingiva }\end{array}$ & $\mathbf{N}$ & $\begin{array}{c}\text { Kelompok } \\
\mathbf{A}(\boldsymbol{\%})\end{array}$ & $\mathbf{N}$ & $\begin{array}{c}\text { Kelompok } \\
\mathbf{B}(\boldsymbol{\%})\end{array}$ \\
\hline $\mathbf{1 .}$ & Sehat & 0 & $0 \%$ & 0 & $0 \%$ \\
\hline $\mathbf{2 .}$ & Ringan & 11 & $55 \%$ & 12 & $60 \%$ \\
\hline 3. & Sedang & 8 & $40 \%$ & 8 & $40 \%$ \\
\hline 4. & Berat & 1 & $5 \%$ & 0 & $0 \%$ \\
\hline & Jumlah & 20 & $100 \%$ & 20 & $100 \%$ \\
\hline
\end{tabular}

Tabel 1 menunjukkan bahwa sebelum perlakuan dilakukan pengukuran peradangan gingiva (gingivitis) untuk kelompok A kondisi gingiva sebagai berikut: gingiva sehat 0 orang $(0 \%)$, peradangan ringan 11 orang $(55 \%)$, peradangan sedang 8 orang $(40 \%)$ dan untuk peradangan berat 1 orang $(5 \%)$. Kelompok B kondisi gingiva sebagai berikut: 
gingiva sehat 0 orang $(0 \%)$, peradangan ringan 12 orang $(60 \%)$, peradangan sedang 8 orang $(40 \%)$, peradangan berat 0 orang $(0 \%)$. Pengukuran gingival index sesudah diberi perlakuan kelompok A dan kelompok B kondisi peradangan gingiva dapat dilihat pada tabel 4 di bawah ini :

Tabel 2 : Distribusi frekuensi peradangan gingiva sesudah perlakuan

\begin{tabular}{cccccc}
\hline No. & $\begin{array}{c}\text { Kriteria } \\
\text { peradangan } \\
\text { gingiva }\end{array}$ & $\mathbf{N}$ & $\begin{array}{c}\text { Kelompok } \\
\mathbf{A}(\boldsymbol{\%})\end{array}$ & $\mathbf{N}$ & $\begin{array}{c}\text { Kelompok } \\
\mathbf{B}(\boldsymbol{\%})\end{array}$ \\
\hline $\mathbf{1 .}$ & Sehat & 0 & $0 \%$ & 0 & $0 \%$ \\
\hline 2. & Ringan & 16 & $80 \%$ & 18 & $90 \%$ \\
\hline 3. & Sedang & 4 & $20 \%$ & 2 & $10 \%$ \\
\hline 4. & Berat & 0 & $0 \%$ & 0 & $0 \%$ \\
\hline & Jumlah & 20 & 100 & 20 & $100 \%$ \\
\hline
\end{tabular}

Tabel 2 menunjukkan bahwa sesudah perlakuan kondisi peradangan gingiva pada siswa kelas VIII untuk kelompok A kondisi gingiva sebagai berikut: gingiva sehat 0 orang $(0 \%)$, peradangan ringan 16 orang (80\%), peradangan sedang 4 orang (20\%) dan peradangan berat 0 orang $(0 \%)$. Kelompok B kondisi gingiva sebagai berikut: gingiva sehat 0 orang $(0 \%)$, peradangan ringan 18 orang $(90 \%)$, peradangan sedang 2 orang $(10 \%)$, peradangan berat 0 orang $(0 \%)$.

Hasil pengukuran gingival index sebelum dan sesudah berkumur rebusan daun sirih merah dan daun sirih hijau pada kelompok A dan B. Lebih jelasnya dapat dilihat pada tabel 3 di bawah ini :

Tabel 3. Distribusi frekuensi hasil hasil pemeriksaan gingival index siswa kelas VIII sebelum dan sesudah berkumur rebusan daun Sirih Merah dan Hijau

\begin{tabular}{c|c|c|c|c|c|ccc}
\hline & \multicolumn{3}{|c|}{ Kelompok A (Sirih Merah) } & \multicolumn{3}{c}{ Kelompok B (Sirih Hijau) } \\
\cline { 2 - 9 } & Sebelum & $\%$ & Sesudah & $\%$ & Sebelum & $\%$ & Sesudah & $\%$ \\
\hline Sehat & 0 & $0 \%$ & 0 & $0 \%$ & 0 & $0 \%$ & 0 & $0 \%$ \\
\hline Ringan & 11 & $55 \%$ & 16 & $80 \%$ & 12 & $60 \%$ & 18 & $90 \%$ \\
\hline Sedang & 8 & $40 \%$ & 4 & $20 \%$ & 8 & $40 \%$ & 2 & $10 \%$ \\
\hline Berat & 1 & $5 \%$ & 0 & $0 \%$ & 0 & $0 \%$ & 0 & $0 \%$ \\
\hline Jumlah & 20 & $100 \%$ & 20 & $100 \%$ & 20 & $100 \%$ & 20 & $100 \%$ \\
\hline
\end{tabular}

Tabel 3 menunjukkan bahwa sesudah perlakuan kondisi peradangan gingiva pada siswa kelas VIII untuk kelompok A kondisi gingiva sebagai berikut : gingiva sehat 0 orang $(0 \%)$ dan tidak ada perubahan, peradangan ringan 11 orang $(55 \%)$ berubah menjadi 16 orang $(80 \%)$, peradangan sedang 8 orang $(40 \%)$ berubah menjadi 4 orang $(20 \%)$ dan peradangan berat 1 orang $(5 \%)$ berubah menjadi 0 orang $(0 \%)$. Tabel 6 menunjukkan bahwa sesudah perlakuan kondisi peradangan gingiva pada siswa kelas VIII untuk kelompok B kondisi gingiva sebagai berikut : gingiva sehat 0 orang $(0 \%)$ dan tidak ada perubahan, peradangan ringan 12 orang $(60 \%)$ berubah menjadi 18 orang $(90 \%)$, peradangan sedang 8 orang $(50 \%)$ berubah menjadi 2 orang $(10 \%)$, peradangan berat 0 orang $(0 \%)$ dan tidak ada perubahan 
Home page: http://ejurnal.poltekkestasikmalaya.ac.id/index.php/jikg

\section{Tabel 4. Distribusi frekuensi nilai rata-rata Gingiva Index sebelum dan sesudah berkumur rebusan Daun Sirih Merah dan Daun Sirih Hijau}

\begin{tabular}{|c|c|c|c|}
\hline Jenis Daun Sirih & $\begin{array}{c}\text { Nilai rata-rata GI } \\
\text { sebelum }\end{array}$ & $\begin{array}{c}\text { Nilai rata-rata GI } \\
\text { sesudah }\end{array}$ & Selisih \\
\hline Sirih Merah & 0,935 & 0,700 & 0,235 \\
\hline Sirih Hijau & 1,025 & 0,535 & 0,490 \\
\hline
\end{tabular}

Tabel 4 menunjukkan selisih penurunan kriteria gingiva index sesudah perlakuan daun Sirih Merah dan Daun Sirih Hijau, yaitu nilai rata-rata sebelum berkumur daun Sirih Merah adalah 0,935 dan sesudah berkumur 0,700, dan selisihnya 0,235. Nilai rata-rata sebelum berkumur daun Sirih Hijau adalah 1,025 dan sesudah berkumur 0,535, dan selisihnya 0,490 . Berdasarkan selisih nilai rata-rata gingiva index sebelum dan sesudah perlakuan, responden kelompok B yang mendapatkan perlakuan berkumur rebusan daun sirih hijau menghasilkam penurunan nilai rata-rata gingiva index yang relatif lebih banyak yaitu sebesar 0,490, sedangkan responden kelompok A yang mendapat perlakuan berkumur rebusan daun sirih merah hanya menghasilkan nilai rata-rata gingiva index 0,235 .

Menurut Nurhidayati, dkk (2012) Hasil determinasi tanaman yang dilakukan Laboratorium Herbarium Bogoriense, Pusat Penelitian-LIPI, Bogor diperoleh hasil bahwa sampel penelitian tersebut adalah tanaman sirih merah dan sirih hijau, Hasil destilasi uap dari $\pm 10 \mathrm{~kg}$ daun segar diperoleh minyak atsiri dari daun sirih merah dan sirih hijau masing-masing $0,035 \%$ dan $0,27 \%$. Dengan demikian daun sirih hijau mengandung minyak atsiri lebih kurang delapan kali lebih banyak daripada daun sirih merah. Menurut Mariyanti, dkk. (2012), bahwa terdapat kesamaan kandungan pada daun sirih hijau dan daun sirih merah, keduanya memiliki kandungan minyak atsiri yang terdiri dari kavikol, eugenol, flavonoid dan tanin. Sedangkan perbedaannya yaitu terdapat perbedaan besar kandungan minyak atsiri yang terkandung dalam ekstrak daun sirih hijau dan ekstrak daun sirih merah. Kandungan minyak atsiri ekstrak daun sirih hijau lebih besar dari ekstrak daun sirih merah. Kandungan minyak atsiri pada ekstrak daun sirih hijau 1-4,2\% sedangkan kandungan minyak atsiri pada ekstrak daun sirih merah sebesar 0,727\%. Perbedaan konsentrasi minyak atsiri tersebut juga mempengaruhi konsentrasi kandungan kavikol yang memiliki daya bunuh bakteri lima kali lebih besar dari phenol biasa di dalamnya. Kemungkinan perbedaan tersebut menyebabkan ekstrak daun sirih hijau mempunyai efektifitas antibakteri yang lebih besar dari pada ekstrak daun sirih merah

\section{KESIMPULAN}

Dari hasil penelitian ini dapat dikemukakan beberapa kesimpulan, yaitu : 1) Perlakuan daun sirih merah dan daun sirih hijau pada responden, sama-sama efektif meringankan puberty gingivitis pada murid kelas VIII MTs Nurul Falah Kawalu Kota Tasikmalaya; 2) Adapun yang membuat rebusan daun sirih hijau memiliki tingkat keefektifan lebih tinggi dari rebusan daun sirih merah yaitu karena kandungan minyak atsiri daun sirih hijau lebih banyak dibandingkan dengan kandungan minyak atsiri dalam daun sirih merah 


\section{DAFTAR PUSTAKA}

Arikunto. 2010. Prosedur Penelitian. Jakarta: PT. Rineka Cipta.

BkkbN. 2012. Suplemen Bimbingan Teknis Kesehatan Reproduksi Pubertas. Jakarta.

Depkes, RI. 2002. Buku Pegangan materi Kesehatan Gigi dan Mulut untuk

Kegiatan KIA di Posyandu (UKGMD). Direktorat Jenderal Pelayanan Medik, Direktorat Kesehatan Gigi, Jakarta.

Kartono, Kartini. 2007. Psikologi Anak. Bandung: Mandar Maju.

Kementerian Kesehatan, RI. 2010. Rencana Strategis Kementerian Kesehatan Tahun 2010-2014. Jakarta.

Komunitas Dian Aksara. Tanaman Obat. Bandung: Puri Pustaka.

Kristiani., dkk. 2008. Ilmu Penyakit Gigi dan Mulut. Tasikmalaya.

Mahendra, B. 2006. 13 Jenis Tanaman Obat Ampuh. Jakarta: Penenbar Swadaya.

Mahfoedz dan Zein. 2005. Menjaga Kesehatan Gigi dan Mulut Anak-anak dan Ibu Hamil. Yogyakarta: Fitramaya.

Mariyatin H., Widyowati E., Lestari S. 2012. Efektivitas Antibakteri Ekstrak Daun Sirih Merah (Piper Crocatum) dan Sirih Hijau (Piper Betle L.) sebagai Bahan Alternatif Irigasi Saluran Akar (The Efectiveness of Red Piper Betle (Piper Crocatum) and Green Piper Betle (Piper Bettle L) Leaf Extracts as Root Canal Irrigation Alternative Materials). Jurnal Jurusan Kedokteran Gigi UNEJ. Jember.

Maulana. H. D. J. 2009. Promosi Kesehatan. Jakarta: EGC.

Mumpuni dan Pratiwi. 2013. 45 Masalah dan Solusi Penyakit Gigi dan Mulut. Yogyakarta: Rapha Publishing.

Mega, N., Kusmana, A., Nugroho, C., Kamelia, E. and Miko, H., 2019. Efektifitas Larutan Buah Bit dan Larutan Buah Naga Merah Sebagai Bahan Identifikasi Plak Gigi Pada Mahasiswa Tingkat 1 Jurusan Keperawatan Gigi Poltekkes Kemenkes Tasikmalaya. Actual Research Science Academic, 4(1), pp.24-30.

Nisa., dkk. 2014. Ekstrasi Daun Sirih Merah (Piper Batle Crocatum) dengan Metode Microwave Assisted Extraction (MAE). Jurnal Fakultas Teknologi Pertanian. Malang.

Notoatmodjo. 2005. Metodologi Penelitian Kesehatan. Jakarta: PT. Asdi Mahasatya.

Nurhidayati L., Desmiaty L., Mariani S., Penetapan Kadar Eugenol dalam Minyak

Atsiri dari Daun Sirih Merah (Piper cf fragile Benth.) dan Sirih Hijau (Piper betle L.) secara Kromatografi Gas. Jurnal Fakultas Farmasi Universitas Pancasila. Jakarta.

Oktaviani. 2012. Uji banding efektivitas ekstrak daun sirih merah (piper crocatum) dengan zinc pyrithione $1 \%$ terhadap pertumbuhan pityrosporum ovale pada penderita berketombe. Fakultas Kedokteran Universitas Diponegoro. Semarang.

Putri, M. H., Herijulianti, E. dan Nurjanah, N. 2010. Ilmu Pencegahan Penyakit Jaringan Keras danJaringan Pendukung Gigi. Jakarta: EGC.

Rosdiana dan Pratiwi. 2014. Khasiat Ajaib Daun SirihTumpas Berbagai Penyakit. Jakarta: PADI. 
Sakri., dkk. 2012. 1001 Khasiat dan Manfaat Jamu Godog. Yogyakarta : Diandra Pustaka Indonesia.

Santoso. 1998. Tanaman Obat Keluarga. Yogyakarta: KANISIUS.

Sariningsih, Endang. 2014. Gigi Busuk dan Poket Periodontal Sebagai Fokus Infeksi. Jakarta: Elex Media Komputindo.

Sudewo, Bambang. 2010. Basmi Penyakit dengan Daun Sirih Merah. Jakarta: Argomedia Pustaka.

Sulistyowati dan Senewe. 2010. Pola Pencarian Pengobatan Dan Perilaku Beresiko Remaja Di Indonesia (Analisis Lanjut Data Riskesdas 2007). Jurnal Ekologi Kesehatan.

Suryawati. 2010. 100 Pertanyaan PentingPerawatan Gigi Anak. Jakarta : DIAN RAKYAT.

Suseno. 2013. Sehat dengan Daun. Yogyakarta: Suka Buku.

Wijayakusuma, H. 2008. Ramuan Lengkap Herbal Taklukan Penyakiit. Jakarta: Pustaka Bunda.

Wardhany, Indri. 2008. Sirih Merah. Yogyakarta: Balai Pengkajian Teknologi Pertanian.

Zulkifli. 2005. Psikologi Perkembangan. Bandung: Remaja Rosdakarya. 